\title{
Fentanyl Hydrochloride
}

National Cancer Institute

\section{Source}

National Cancer Institute. Fentanyl Hydrochloride. NCI Thesaurus. Code C61762.

The hydrochloride salt form of fentanyl, a synthetic, lipophilic phenylpiperidine opioid agonist with analgesic and anesthetic properties. Fentanyl selectively binds to the mureceptor in the central nervous system (CNS) thereby mimicking the effects of endogenous opiates. Stimulation of the mu-subtype opioid receptor stimulates the exchange of GTP for GDP on the G-protein complex and subsequently inhibits adenylate cyclase. This results in a decrease in intracellular cAMP and leads to a reduction in the release of neurotransmitters such as substance P, GABA, dopamine, acetylcholine and noradrenaline. The analgesic effect of fentanyl is likely due to its metabolite morphine, which induces opening of G-protein-coupled inwardly rectifying potassium (GIRK) channels and blocks the opening of $\mathrm{N}$-type voltage-gated calcium channels, thereby resulting in hyperpolarization and reduced neuronal excitability. 